\title{
Urbanization Impacts on the Climate in Europe: Numerical Experiments by the PSU-NCAR Mesoscale Model (MM5)
}

\author{
K. Trusilova AND M. Jung \\ Max Planck Institute for Biogeochemistry, Jena, and International Max Planck Research School for Earth Ecosystem Modeling, \\ Hamburg, Germany \\ G. CHurkinA \\ Max Planck Institute for Biogeochemistry, Jena, Germany \\ U. KARSTENS \\ Max Planck Institute for Biogeochemistry, Jena, and Max Planck Institute for Meteorology, Hamburg, Germany \\ M. HEIMANN \\ Max Planck Institute for Biogeochemistry, Jena, Germany \\ M. Claussen \\ Max Planck Institute for Meteorology, and Meteorological Institute, University of Hamburg, Hamburg, Germany
}

(Manuscript received 23 October 2006, in final form 30 August 2007)

\begin{abstract}
The objective of this study is to investigate the effects of urban land on the climate in Europe on local and regional scales. Effects of urban land cover on the climate are isolated using the fifth-generation Pennsylvania State University-National Center for Atmospheric Research (PSU-NCAR) Mesoscale Model (MM5) with a modified land surface scheme based on the Town Energy Budget model. Two model scenarios represent responses of climate to different states of urbanization in Europe: 1) no urban areas and 2) urban land in the actual state in the beginning of the twenty-first century. By comparing the simulations of these contrasting scenarios, spatial differences in near-surface temperature and precipitation are quantified. Simulated near-surface temperatures and an urban heat island for January and July over a period of $6 \mathrm{yr}$ (2000-05) agree well with corresponding measurements at selected urban areas. The conversion of rural to urban land results in statistically significant changes to precipitation and near-surface temperature over areas of the land cover perturbations. The diurnal temperature range in urbanized regions was reduced on average by $1.26^{\circ} \pm 0.71^{\circ} \mathrm{C}$ in summer and by $0.73^{\circ} \pm 00.54^{\circ} \mathrm{C}$ in winter. Inclusion of urban areas results in an increase of urban precipitation in winter $\left(0.09 \pm 00.16 \mathrm{~mm} \mathrm{day}^{-1}\right)$ and a precipitation reduction in summer $\left(-0.05 \pm 0.22 \mathrm{~mm} \mathrm{day}^{-1}\right)$.
\end{abstract}

\section{Introduction}

Urbanization is one of the most evident examples of human modification of the earth. Urban land accounts for less than $2 \%$ of the earth's land area, but this proportion is growing rapidly as more cities expand into natural ecosystems and agricultural areas. According to the United Nations Information Service (UNIS), the

Corresponding author address: K. Trusilova, Max Planck Institute for Biogeochemistry, Hans-Knoell Str. 10, 07745 Jena, Germany.

E-mail: ktrusil@bgc-jena.mpg.de proportion of the population living in urban areas is still expected to increase to $82 \%$ by 2030 . However, our understanding of the role that urbanization plays in earth climate system processes is incomplete. Recently, several issues arose that refer to the "urban environment + climate system" linkage, such as how land use and land cover are linked to climate and weather (Shepherd and Jin 2004).

The landscape alteration through urbanization involves the transformation of the radiative and aerodynamic characteristics of the land surface and results in changes of the water cycle and planetary boundary layer. Several studies focused on different aspects of 
urban environments and their influence on climate: variable patterns of extreme temperatures within urban areas (González et al. 2005; Jin et al. 2005; Ca et al. 1998; Jauregui 1991; Huang et al. 1987; Bernatzky 1982), urban heat islands (UHIs; Atkinson 2002; Borghi et al. 2000; Brunetti et al. 2000), contributions of urban environments to global warming (Parker 2004; Jones et al. 1990; Wood 1988; Kukla et al. 1986), high $\mathrm{CO}_{2}$ emissions over urban areas (Koerner and Klopatek 2002; Idso et al. 2001), changes of precipitation (Dixon and Mote 2003; Rosenfeld 2000; Huff and Changnon 1973), and reduced air moisture and evaporation in cities (Mayer et al. 2003; Grimmond and Oke 1999). Most of these studies investigated effects of individual urban areas on local climates, while little is still known about impacts of urbanization on a regional scale on which many policymakers traditionally operate. In our study, we focus on regional climate impacts of multiple urban areas.

Kalnay and Cai (2003) analyzed surface temperature observations from 1950-99 in the continental United States. The authors suggested that half of the observed reduction of the diurnal temperature range (DTR) is caused by land-use changes (including urbanization), which contribute to the mean surface warming by $0.27^{\circ} \mathrm{C}$ per century. However, this study was unable to separate the effects of urban land cover change from the effects caused by changes in other land-use types because this requires observations in somewhat unrealistic conditions: before and after urbanization. Because of difficulties in making such observations, we utilize a modeling approach to estimate effects of urbanization on the regional climate.

Lamptey et al. (2005) explored climatic effects of urban and agricultural land cover transformation in the northeastern United States using a regional modeling approach. The authors found that because of the land cover change in urban sites, the near-surface temperature increased by $0.8 \mathrm{~K}$ in summer and by $1.0 \mathrm{~K}$ in winter, on average. However, the authors performed a model simulation on a coarse $36-\mathrm{km}$ scale and used a very simple parameterization for representing urban land.

In this study, we examine impacts of the urban land use in Europe on local and regional scales. We update the urban mask for Europe and use a regional model with a modified land surface scheme for a more detailed representation of urban land at the spatial scale of $10 \mathrm{~km}$. We focus on changes of the near-surface temperatures and precipitation between two different states of urbanization: 1) a hypothetical situation in which no urban area is present and 2) a situation in which urban land has an extent as in 2000-05. We quan- tify the magnitude of the climate response to the urban land use as a single climate forcing parameter. Although changes of greenhouse gas concentrations induced by human activities may affect the atmospheric circulation and, consequently, influence urban temperatures by changing the atmospheric transmissivity (Stanhill and Kalma 1995), it is beyond the scope of this paper.

\section{Methods}

\section{a. Regional model MM5}

We used the limited-area numerical weather prediction fifth-generation Pennsylvania State UniversityNational Center for Atmospheric Research (NCAR) Mesoscale Model (MM5; Grell et al. 1995) for our simulations. This nonhydrostatic model simulates and predicts mesoscale atmospheric circulation and is typically used on a regional scale. The distinction between urban and nonurban areas within its land surface scheme, which is based on the community Noah land surface model (LSM; Ek et al. 2003; Chen and Dudhia 2001a,b), is handled by modifications of specific land surface parameters. Although the physical schemes of the model can represent dominant impacts of urban land cover on the atmosphere, the near-surface processes are insufficiently resolved. As the model was not explicitly designed to distinguish between boundary layer and canopy layer phenomena, such as heat island or limited evaporation in urban areas, the effects of the complex urban surface on the energy balance could be parameterized only indirectly. On the scale of our interest $(10 \mathrm{~km})$, geometrical properties of the urban canopy as well as thermal and radiative properties of heterogeneous urban materials become important. To account for this, we modified the existing land surface scheme for the urban land cover type using a singlelayer urban canopy model of Masson (2000).

\section{b. Modifications of the land surface model}

The urban surface scheme for this study had to be generalized to represent large horizontal scales (10-100 $\mathrm{km})$ and to be able to capture radiative budgets, momentum, and turbulent heat and ground fluxes from heterogeneous urban surfaces. In contrast to more comprehensive urban surface schemes, which include parameterizations for the canyon orientation (Martilli et al. 2002; Kusaka et al. 2001) and heterogeneous building morphology (Martilli et al. 2002), the Town Energy Budget (TEB) model (Masson 2000) includes a simplified description of the town geometry. It assumes that all buildings are of the same shape and are set at the same distance away from each other with no dis- 
crete street orientation. Such generalization allows model applicability for multiple urban areas in the large domain in this study. A single-layer urban canopy model (UCM), which includes a TEB surface parameterization scheme for urban nonvegetated land and an LSM for urban vegetated land, was incorporated into the land surface scheme of the atmospheric model. The TEB in the UCM predicts three urban surface temperatures: for roofs, walls, and roads. The TEB in the UCM allows the representation of the radiation trapping within the urban canopy; reflected by building walls and roads, incoming direct radiation can be absorbed and/or reflected again by roads and wall surfaces. The model includes parameterization of the limited surface evaporation from impervious urban surfaces. The LSM in the UCM predicts the temperature over urban vegetated surfaces. The rooftop level and the vegetation canopy top level in the UCM correspond to the lowest level of the atmospheric model. At this level, the three turbulent flux contributions (from roofs, street canyons, and vegetated surfaces) are averaged proportionally to their horizontal area fractions in the grid of the atmospheric model.

The water reservoir of the urban canopy in the model has a small capacity $\left(1 \mathrm{~kg} \mathrm{~m}^{-2}\right.$ for roofs and roads), and the water in excess from roofs and roads is "lost" as runoff. These surfaces are impervious and impenetrable to water, but a certain fraction of each of them can be covered by water, which is immediately available for evaporation, while the remaining surface is assumed to be dry.

The UCM predicts heat and moisture fluxes from heterogeneous urban surfaces, includes additional anthropogenic heat and moisture fluxes from the urban canopy to the atmosphere, and accounts for thermophysical properties of different urban surfaces. Outgoing heat fluxes from these surfaces are aggregated into energy and momentum exchange fluxes between the urban canopy and the atmosphere.

The UCM scheme was integrated into the MM5 model as a subroutine, which calculates the soil moisture, soil temperature, skin temperature, snowpack (water equivalent), and all terms of the surface energy balance and surface water balance for urban areas.

The coupled MM5-UCM system uses one urban land-use class as input, which is characterized by a set of parameters. When only a particular urban area is considered, the parameters could be set to represent its specifics (e.g., built-up density, building height, vegetation fraction). Problems occur when multiple heterogeneous urban areas are included in the study domain: none can be parameterized individually because such information is difficult to collect and to incorporate into
TABLE 1. Parameters for the urban canopy model that represent a typical midsize European city.

\begin{tabular}{llcc}
\hline \hline Symbol & Designation of symbol & Value & Units \\
\hline$a_{\text {town }}$ & $\begin{array}{l}\text { Fractional area occupied by } \\
\text { artificial materials }\end{array}$ & 0.85 & - \\
$a_{\text {bld }}$ & $\begin{array}{l}\text { Fractional area occupied by } \\
\text { buildings }\end{array}$ & 0.50 & - \\
& $\begin{array}{l}\text { Building height } \\
h\end{array}$ & 20.0 & $\mathrm{~m}$ \\
$l$ & $\begin{array}{l}\text { Building "length" along a } \\
\text { road }\end{array}$ & 20.0 & $\mathrm{~m}$ \\
$w$ & $\begin{array}{l}\text { Width of a street canyon } \\
h / l\end{array}$ & 20.0 & $\mathrm{~m}$ \\
$h / w$ & Building aspect ratio & 1.0 & - \\
$\mathrm{z} 0_{\text {town }}$ & Canyon aspect ratio & 1.0 & - \\
& Roughness length for & 2.0 & $\mathrm{~m}$ \\
\hline
\end{tabular}

the model, but an average parameterization for all urban areas should be applied uniformly. In this study, we set the thermal and radiative properties of urban roofs, walls, and roads for all cities to values as in the work of Masson (2000).

Geometrical properties such as building height, building aspect ratio, and canyon aspect ratio, as well as the fraction of vegetation cover of urban areas, were averaged over available data (Lavalle et al. 2002) and were set to values representing a typical midsize European city (Table 1). Thus, the uniform parameterization of the urban canopy for all urban areas represents main impacts of urban land to the atmosphere and allows the analysis of the sensitivity of those impacts to different climate conditions and city sizes. However, it might be a source of large uncertainties in weather prediction.

\section{c. Mapping urban areas}

Two land cover maps were created for representing different states of urbanization: one that includes no urban area (NOU map) and another with the distribution of urban areas in 2000-05 (URB map). The NOU map was derived from the Global Land Cover Characterization (GLCC) from the U.S. Geological Survey land-use classification by replacing urban pixels with the dominating land-use type of neighbor pixels. For the present state of urban mask, we had to produce a new URB map because the GLCC land-use classification (Loveland et al. 2000), which is commonly used in MM5 simulations, strongly underrepresents urban areas in Europe (Fig. 1a). We used several available datasets to update the spatial distribution of cities.

The Coordinated Information on the European Environment from the Europe Environment Agency (EUCORINE) land cover database, which was derived from higher-resolution satellite imagery (Landsat), has a spatial resolution of $250 \mathrm{~m}$ and a detailed representation of urban land. However, this database covers 

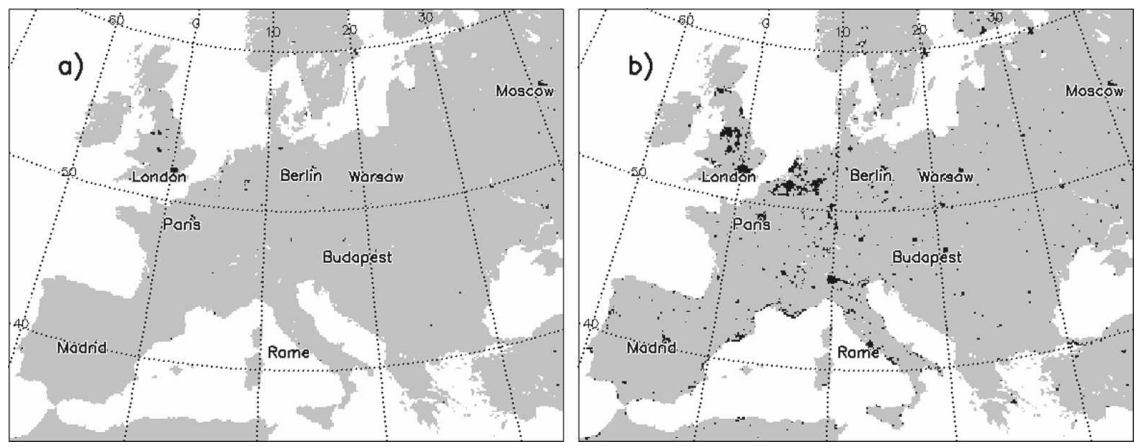

FIG. 1. (a) The standard GLCC urban mask and (b) the new URB map urban mask at a spatial resolution of $10 \mathrm{~km}$ (urban areas are shown in black). The standard GLCC map contains only $0.3 \%$ of urban land, while the new map contains $2.8 \%$.

only a part of Europe and thus cannot directly be used as an input for the model. We used CORINE as a reference for the evaluation of existing global land cover classifications on the spatial resolution of $1 \mathrm{~km}$. Statistical and visual comparison of GLCC, Global Land Cover 2000-Joint Research Centre from European Commission Directorate General (GLC2000), and Moderate Resolution Imaging Spectroradiometer (MODIS) land cover type maps from the National Aeronautic and Space Administration (NASA) with CORINE revealed that none of them captures urban areas in Europe well enough.

The GLCC and GLC2000 underestimate the total urban area in Europe (omission errors), while individual pixels that are mapped as urban in these datasets generally agree with the CORINE map and can be assumed to be correct. Urban areas in the MODIS land cover product occupy roughly the same total area as in CORINE, but large cities are mapped larger than they appear in CORINE (i.e., they are falsely classified as urban; commission errors). A general problem that appears across all the 1-km land cover classifications is that the small towns and villages are either altogether absent or mapped too small.

To produce a better map of urban areas at the spatial resolution of $1 \mathrm{~km}$, we used a simple method that makes use of the idea of "convergence of evidence." Five urban masks from different sources were overlaid and the agreement of at least two layers was used to map urban areas. Beyond the existing land-use classifications of GLCC, GLC2000, and the MODIS land cover product, we derived urban masks from the Landscan population dataset from the Oak Ridge National Laboratory (ORNL) and from the night-light emissions recorded by the Defense Meteorological Satellite Program (DMSP). The latter has previously been used to map urban areas from space (Elvidge et al. 1997, 1999; Imhoff et al. 1997). These two additional urban maps were produced applying a threshold above which a pixel is considered to be urban. These thresholds were derived by statistical comparison of the continuous data fields from Landscan and DMSP with CORINE. The thresholds (32 for DMSP and 360 for Landscan) were chosen where the agreement with the CORINE urban class was the highest.

The newly derived URB map (Fig. 1b) appears to be of enhanced quality in comparison with existing classifications. However, it underestimates the urban area of Europe by $\sim 10 \%$; while large cities are mapped slightly too large, this effect is overcompensated for by small villages that are not present in the mask. The new URB map was used in the model scenario that represents the climate in 2000-05.

\section{d. Modeling protocol}

To isolate effects of urbanization on the climate, we performed model simulations according to two scenarios, which correspond to different states of urbanization. The NOU scenario, which used the NOU map, represented a hypothetical situation with no urban areas in the model domain. This was the baseline scenario. The URB scenario represented the climate in the presence of urban areas using the URB map as the model input.

The model domain for this study was centered at $50^{\circ} \mathrm{N}, 15^{\circ} \mathrm{E}$, with a grid size of $10 \mathrm{~km}$, and covered most of geographical Europe (Fig. 1). It was nested in an intermediate domain with a $30-\mathrm{km}$ spatial resolution (not shown) to avoid direct influences from boundary conditions. The meteorological conditions at lateral boundaries of the intermediate domain were taken from the $1^{\circ}$-resolution final-analysis National Centers for Environmental Prediction (NCEP) dataset of 2000-05. The forcing at the boundaries was applied every $12 \mathrm{~h}$, at 0000 and 1200 UTC of each simulated day. An additional boundary condition for the UCM- 
the inner temperature of buildings-was set to the constant of $20^{\circ} \mathrm{C}$ for all simulations.

The model runs were restricted to periods in which significant effects of urban areas on the climate can be expected, given the large computational costs of simulations. Previous investigations revealed that the strongest urban heat island-one of the major urban perturbations of the environment-occurs in both winter (Montávez et al. 2000) and summer (Bottyan et al. 2005; Unger et al. 2001). Thus, we chose to simulate January and July of each year from 2000 to 2005. The model was run for one-month periods. Each simulation started at the beginning of the month and ended at the end of the month. Model output was written every $3 \mathrm{~h}$.

The data for the model initialization at lateral boundaries were chosen according to the following criteria: 1) be representative of long-term climate averages for $\mathrm{Eu}$ rope, 2) provide all necessary data fields for the model initialization, and 3) have a fine spatial resolution. The chosen final analysis NCEP dataset has an advantage of a finer spatial resolution $\left(1^{\circ}\right)$ as compared with other available datasets $\left(2.5^{\circ}\right.$; NCEP reanalysis); however, it only begins in late 1999 while reanalysis datasets typically cover the entire second half of the twentieth century. To prove that the chosen period of 2000-05 is representative of the average climate in Europe, we calculated the average daily temperature $\left(T_{2000-2005}\right)$ and the daily precipitation $\left(\mathrm{PR}_{2000-2005}\right)$ and compared them with the temperature $\left(T_{1980-2005}\right)$ and precipitation ( $\left.\mathrm{PR}_{1980-2005}\right)$ calculated over the 1980-2005 period using the NCEP reanalysis dataset. The comparison revealed no significant differences between values of compared variables: $T_{1980-2005}=19.2^{\circ} \pm 0.9^{\circ} \mathrm{C}$ versus $T_{2000-2005}=19.4^{\circ} \pm 0.8^{\circ} \mathrm{C}$ for July and $T_{1980-2005}=0.1^{\circ} \pm$ $1.6^{\circ} \mathrm{C}$ versus $T_{2000-2005}=0.0^{\circ} \pm 1.1^{\circ} \mathrm{C}$ for January; $\mathrm{PR}_{1980-2005}=2.81 \pm 0.63 \mathrm{~mm}^{-1 a y}{ }^{-1}$ versus $P R_{2000-2005}=$ $2.94 \pm 0.33 \mathrm{~mm}^{1980-2005}{ }^{-1}$ for July and $P R_{1980-2005}=1.51 \pm$ $0.38 \mathrm{~mm}$ day $^{-1}$ versus $P R_{2000-2005}=1.54 \pm 0.35 \mathrm{~mm}$ day $^{-1}$ for January. Thus, the chosen final analysis NCEP dataset for the period of 2000-05 meets all three criteria: contains all data fields necessary for the model initialization, has the spatial resolution of $1^{\circ}$, and is representative of the climate in Europe. The combination of these characteristics makes the dataset a fair choice.

For the model setup, we chose a simple single-cloud cumulus parameterization scheme with clouds represented as a combination of one updraft flux and one downdraft flux (Grell et al. 1995), which is typically used in an MM5 model on the spatial resolution of $10-30 \mathrm{~km}$. For the parameterization of nonliquid precipitation, we used the simple ice scheme of Dudhia (1989), which allows no supercooled clouds and imme- diate melting of snow below melting level. For the planetary boundary layer (PBL) parameterization, the Medium-Range Forecast (MRF) scheme of Hong and Pan (1996) was used. The abovementioned parameterization schemes are included in the standard version 3.7 of the MM5 model.

In the TEB of the UCM scheme for the calculation of the canyon temperature and humidity, the anthropogenic sensible heat flux due to traffic $\left(40 \mathrm{~W} \mathrm{~m}^{-2}\right)$ was added at the road level. The small anthropogenic sensible heat flux $\left(5 \mathrm{~W} \mathrm{~m}^{-2}\right)$ and latent heat flux $(5 \mathrm{~W}$ $\mathrm{m}^{-2}$ ) due to industry were added at the roof level for the calculation of the turbulent fluxes on the town scale. The values of fluxes were taken from the work of Masson (2000). The soil moisture content was initialized at the beginning of each simulation (each month) over the domain by the available data fields (soil temperature and soil moisture at depths of $10 \mathrm{~cm}$ and $2 \mathrm{~m}$ ) in the final analysis NCEP dataset and was updated at every model time step.

For nonurban surfaces, the standard LSM land surface scheme was used, and for urban surfaces, the UCM subroutine was called upon. The coupled LSM-UCM scheme was used for calculating the surface fluxes into the PBL scheme and, as the diagnostic equation, for calculating the skin temperature and the near-surface temperature at $2 \mathrm{~m}$ above ground. Radiative and thermal properties of the vegetation cover (albedo, roughness length, emissivity, thermal inertia, etc.) remained fixed through all simulations for winter (January) and summer (July); changes of these properties due to vegetation dynamics were not included in the LSM.

\section{e. Analysis of the simulations}

The adequacy of the model was evaluated by comparing simulated (the URB scenario) and measured near-surface temperatures and UHIs for several sites. Observations of the near-surface ( $2 \mathrm{~m}$ above ground) temperature and/or of the difference in the temperatures between urban land and its rural surrounding (e.g., UHI) were extracted for eight cities from the available literature (Alonso et al. 2003; Unger et al. 2001; Montávez et al. 2000; Klysik and Fortuniak 1999; Hupfer and Chmielewski 1990; Müller 1996) and other publicly available sources of information (e.g., www. unibas.ch; www.wetteronline.de; www.stadtklima.de). For the comparison with model output on the $10-\mathrm{km}$ grid, only observations that represent the thermal regime of a region of $0.5-10 \mathrm{~km}$ (a whole city or a large part of it) were used. Observations on the local scale $(0.01-0.10 \mathrm{~km})$ were not taken into the analysis.

Effects of urban land use were detected via significance tests of the differences in temperature and pre- 
cipitation between the URB and NOU model scenarios. The analysis was performed separately for each grid point of the model domain, assuming their independence from each other (no spatial autocorrelation was taken into account). Time series corresponding to January and July were analyzed separately to detect seasonal differences in urban land-use effects. Before the significance test was applied, the interannual variability term was subtracted from the analyzed time series. For the model output time series $x$ of the month $\mathrm{im}$, the mean $\overline{x_{\mathrm{im}}}=\sum_{\mathrm{id}=1}^{30} x_{\mathrm{id}}$ was subtracted from each element id (day) of $x: x_{\text {id }}^{\prime}=x_{\text {id }}-\overline{x_{\text {im }}}$, where id $=1-30$. Therefore, data series $x^{\prime}$ of different years could be processed in the statistical significance test at once as the time series of the concatenated $\left\{x_{2000}^{\prime}, x_{2001}^{\prime}, x_{2002}^{\prime}\right.$, $\left.x_{2003}^{\prime}, x_{2004}^{\prime}, x_{2005}^{\prime}\right\}$. This data transformation allowed the analysis of seasonal temperature and precipitation time series in the absence of an interannual signal. Because this study focused on urbanization-driven climate changes on the regional scale rather than on feedbacks between urban environments and the global climate change, the simulation period of $6 \mathrm{yr}$ was considered sufficient to perform an accurate statistical analysis of the simulated effects. The statistical analysis of daily differences between the URB and NOU model output was used for estimating effects of urban land on the climate.

Different significance tests were chosen for the analysis of temperature and precipitation time series because of the different character of these data. The statistical filter Mann-Whitney $U$ test was applied to the time series of the diurnal temperature range (maximum - minimum temperature) and this showed highly localized differences between the NOU and URB scenarios. The precipitation data had a high variance in time and space, so a variance-insensitive significance test was necessary. The test needs to be rather sensitive to the sign of precipitation differences to detect a reduction or an increase. Thus, the sign test was chosen for the analysis of daily precipitation time series. For both tests, the confidence level was set to 0.05 and data values of only every second day were taken into the statistical analysis to reduce autocorrelation of the data.

To characterize the spatial expansion of the urban climate anomalies we introduced a regional effect index (REI), which was calculated as the ratio of the total area of affected land to the total area of urban land:

$$
\operatorname{REI}(x)=\frac{A_{\text {aff_rur }}(x)+A_{\text {urb }}}{A_{\text {urb }}},
$$

where $x$ is one of the following variables: maximum diurnal temperature difference $\left(\operatorname{Tmax}_{\mathrm{urb}-\mathrm{nou}}\right)$, mini- mum diurnal temperature difference $\left(\operatorname{Tmin}_{\mathrm{urb}-\mathrm{nou}}\right)$, diurnal temperature range difference $\left(\mathrm{DTR}_{\mathrm{urb}-\mathrm{nou}}\right)$, or precipitation difference $\left(\mathrm{PR}_{\mathrm{urb}-\mathrm{nou}}\right) ; A_{\text {aff-rur }}(x)$ is the total area beyond cities where the differences of $x$ were found; and $A_{\text {urb }}$ is the total area of urban land.

From the definition of $\operatorname{REI}(x)$, it is always greater or equal to 1.0, assuming that the urban land is always affected. If $A_{\text {aff-rur }}(x) \rightarrow 0$, then $\operatorname{REI}(x) \rightarrow 1$ and there is no regional effect. If $\operatorname{REI}(x)$ is significantly greater than 1.0, then the changes of $x$ are regional in character. The significance threshold was set to 0.025 (2.5\% of urban land), which means if $\operatorname{REI}(x)>1.025$, then there is a significant regional effect with respect to the variable $x$.

An additional statistical analysis was performed to find possible dependencies of the magnitude of urban effects and climate conditions of the region where these effects occur. For each urban pixel (upix), the average monthly temperature $\left(T_{\text {nou, upix }}\right)$ and precipitation $\left(\mathrm{PR}_{\text {nou, upix }}\right)$ were calculated for January and July over 6 simulated yr (2000-05) from the NOU model simulation. Then the effects $\operatorname{Tmin}_{\text {urb-nou, upix }}$, Tmax $_{\text {urb-nou, upix }}, \mathrm{DTR}_{\text {urb-nou, upix }}$, and $\mathrm{PR}_{\text {urb-nou, upix }}$, which were extracted for each upix, were correlated to the $T_{\text {nou, upix }}$ and $\mathrm{PR}_{\text {nou, upix }}$. The correlation coefficients were then analyzed.

\section{Results and discussion}

\section{a. Corroboration of model results}

Model simulations of the URB scenario were compared to available observations at several urban sites (Table 2) for the near-surface temperature and the magnitude of the urban heat island. The UHI was calculated as the difference between near-surface temperatures at urban and rural sites. The observed and measured near-surface temperatures were averaged over one month, because the model temporal resolution $(3 \mathrm{~h})$ can represent only the main diurnal temperature variations and not the finescale temperature oscillations.

Modeled temperatures at Berlin, Germany, Madrid, Spain, and Salamanca, Spain, agreed well with observations in both seasons. The modeled UHI at Szeged, Hungary, Lodz, Hungary, and Granada, Spain, compared favorably to the measurements in both simulated seasons, whereas at Basel, Switzerland, only the summer season simulations agreed well with the measurements of the near-surface temperature and UHI. The mismatch between modeled and measured near-surface temperatures in January at Basel and Granada can be explained by the poor representation of the terrain 
TABLE 2. Comparison with available measurements in selected sites of predicted near-surface temperatures and UHIs. Table cells with boldface entries indicate a mismatch by more than $2^{\circ} \mathrm{C}$ between modeled (mod) and observed (obs) temperatures.

\begin{tabular}{|c|c|c|c|c|c|c|c|c|}
\hline \multirow[b]{2}{*}{ Site name } & & & \multicolumn{2}{|c|}{ Near-surface temperature $\left({ }^{\circ} \mathrm{C}\right)$} & \multicolumn{2}{|c|}{ Avg UHI $\left({ }^{\circ} \mathrm{C}\right)$} & \multicolumn{2}{|c|}{ Max UHI $\left({ }^{\circ} \mathrm{C}\right)$} \\
\hline & \multicolumn{2}{|c|}{ Time } & Mod & Obs & Mod & Obs & Mod & Obs \\
\hline \multirow[t]{2}{*}{ Szeged, Hungary } & $99-00$ & Jan & 4.1 & -1.1 & & & 1.5 & 1.4 \\
\hline & & Jul & 23.1 & 22.1 & & & 2.7 & 2.6 \\
\hline \multirow[t]{2}{*}{ Lodz, Hungary } & $92-94$ & Jan & & & & & & \\
\hline & & Jul & 18.5 & 18.4 & & & 1.8 & 2.0 \\
\hline \multirow[t]{2}{*}{ Granada, Spain } & $01-90$ & Jan & 12.3 & 6.4 & 2.1 & 2.5 & 2.5 & 3.0 \\
\hline & & Jul & 28.3 & 25.7 & 4.3 & 1.8 & 4.6 & 3.6 \\
\hline \multirow[t]{2}{*}{ Salamanca, Spain } & $96-98$ & Jan & 6.3 & 5.3 & 1.1 & 2.3 & & \\
\hline & & Jul & 22.5 & 20.9 & 1.8 & 2.7 & & \\
\hline \multirow[t]{2}{*}{ Basel, Switzerland } & - & Jan & 5.0 & 2.2 & & & 3.1 & -2.0 \\
\hline & & Jul & 18.9 & 19.9 & & & 3.8 & 3.0 \\
\hline \multirow[t]{2}{*}{ Moscow, Russia } & - & Jan & -4.8 & -9.9 & & & & \\
\hline & & Jul & 18.3 & 19.0 & & & & \\
\hline \multirow[t]{2}{*}{ Berlin, Germany } & 09-99 & Jan & 1.2 & -0.4 & & & & \\
\hline & & Jul & 16.8 & 17.9 & & & & \\
\hline \multirow[t]{2}{*}{ Madrid, Spain } & - & Jan & 6.5 & 4.9 & & & & \\
\hline & & Jul & 23.3 & 24.2 & & & & \\
\hline
\end{tabular}

complexities within the model on the chosen spatial resolution. The temperature mismatch at Moscow, Russia, and Szeged can be explained by the underestimated snow cover: the predicted snow cover height in Moscow was $13.4 \pm 11.4 \mathrm{~cm}$ and $24.6 \pm 6.2 \mathrm{~cm}$ observed; in Szeged it was $1.1 \pm 3.2 \mathrm{~cm}$ predicted and $4.6 \pm 9.3 \mathrm{~cm}$ observed. The lower value of simulated average snow cover height resulted from a larger number of simulated snow-free days as compared with observations, thus leading to a larger number of days when the albedo of the urban surfaces was low (due to dark colors of roads and roofs) and to higher surface temperatures.

\section{b. Effects of urban land cover on near-surface temperature}

The transformation of vegetated land to urban land resulted in statistically significant differences of nearsurface temperatures (Fig. 2). The temperature alteration due to urban land during wintertime was local in character: only a small territory of nonurban land was affected (REI was close to 1; Table 3). During summertime, the REI was larger, which indicated a stronger regional character of the effect; the maximum temperature and diurnal temperature range were affected over an area about $1 / 3$ larger than the total urban area $(28 \%$ and $37 \%$ ).

The DTR was strongly influenced by the presence of urban areas (Figs. 2a,b). The land-use modification (from vegetated to urban) led to a reduction of the DTR over land of the model domain by $-0.02^{\circ} \pm$ $0.02^{\circ} \mathrm{C}$ in winter and $-0.04^{\circ} \pm 0.06^{\circ} \mathrm{C}$ in summer. These numbers have a great uncertainty because of the large spatial variation of the temperature differences. The largest differences in temperatures were found in areas of urban land where the average reduction of DTR accounted for $-1.26^{\circ} \pm 0.71^{\circ} \mathrm{C}$ in summertime and $-0.73^{\circ} \pm 0.54^{\circ} \mathrm{C}$ in wintertime. The strongest reduction of DTR occurred in cities that are situated in warm, dry climates, such as Madrid and Barcelona in Spain, Milan and Rome in Italy, and Marseille in France, and sometimes reached $-4^{\circ} \mathrm{C}$ (in summer). In summertime, a significant reduction of DTR was also found beyond urban land and accounted for $-0.39^{\circ} \pm 0.39^{\circ} \mathrm{C}$, but it never exceeded $-1.50^{\circ} \mathrm{C}$.

The reduction of DTR resulted from changes of minimum and maximum diurnal temperatures. The average increase of the minimum diurnal temperature (Tmin) over all urban sites accounted for $1.53^{\circ} \pm$ $0.49^{\circ} \mathrm{C}$ in summer and $1.24^{\circ} \pm 0.78^{\circ} \mathrm{C}$ in winter. The maximum diurnal temperature (Tmax) was increased in some regions and reduced in other. These differences of minimum and maximum diurnal temperatures were attributed to changes in geometrical and thermal properties of the perturbed areas as well as their energy balance.

The increase of Tmin has several causes. In combination with lower albedo of urban surfaces (0.08-0.25), which leads to a larger energy absorption during daytime, the limited availability of surface water prevents evaporative cooling of urban areas and offsets the surface-to-atmosphere heat release, thereby extending it to the night and early morning hours. During nighttime, the latent heat flux in urban areas is lower than in rural areas (Figs. 3c,d) because of the limited water availability for evapotranspiration, while the anthropogenic sources of sensible heat persist and contribute to the 

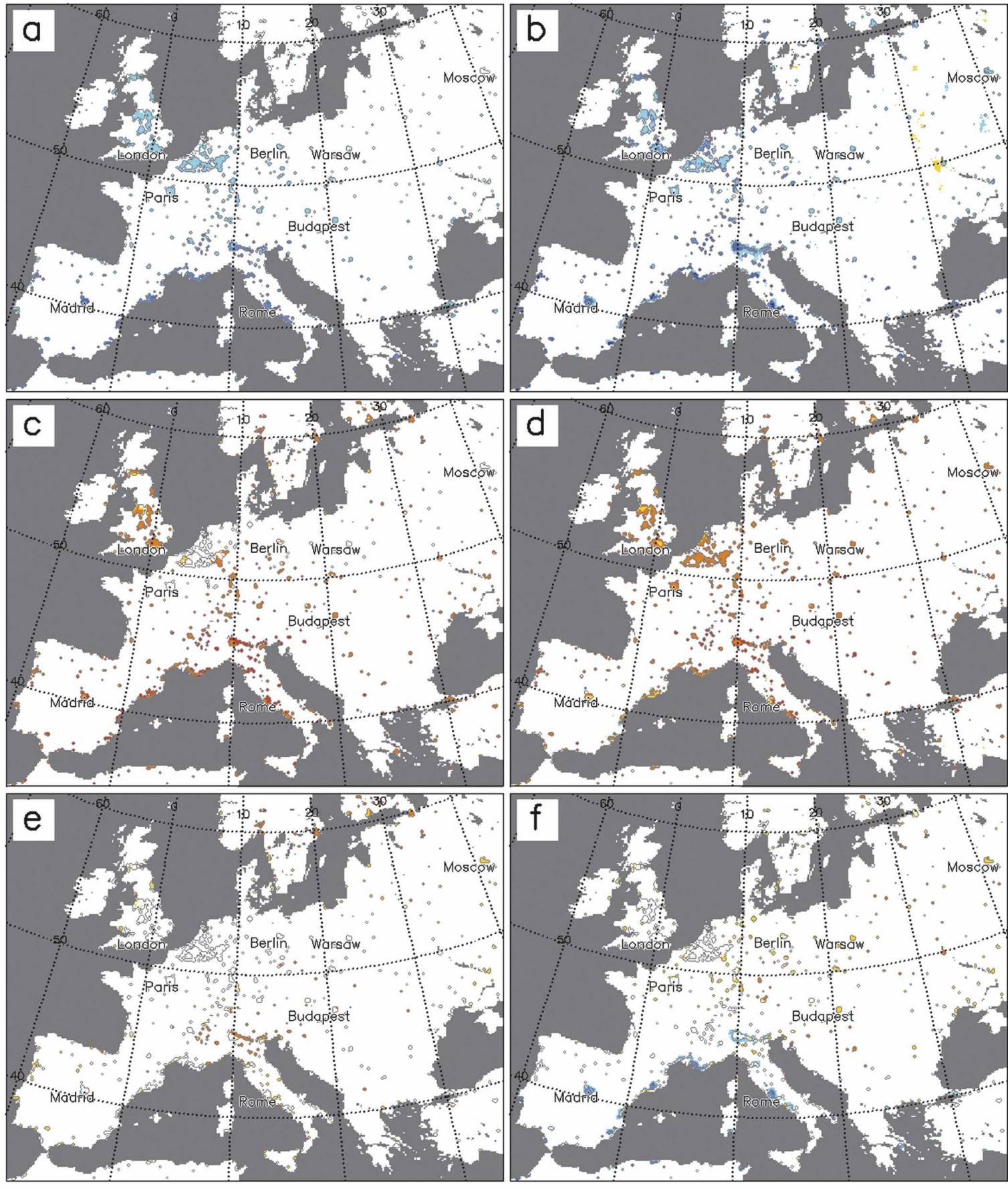

$$
\begin{array}{lllllllll}
-4.0 & -3.0 & -2.0 & -1.0 & 0.0 & +1.0 & +2.0 & +3.0 & +4.0 \\
& & & & & &
\end{array}
$$

FIG. 2. Effects of urban land cover on near-surface temperatures $\left({ }^{\circ} \mathrm{C}\right.$ ) for (left) January and (right) July. (a), (b) Difference in diurnal temperature range $\left(\mathrm{DTR}_{\mathrm{urb}-\mathrm{nou}}\right)$; (c), (d) difference in minimum diurnal temperature $\left(\mathrm{Tmin}_{\mathrm{urb}-\text { nou }}\right)$; and (e), (f) difference in maximum diurnal temperature $\left(\operatorname{Tmax}_{\mathrm{urb}-\mathrm{nou}}\right)$. Colored areas identify places of statistically significant differences between the URB and NOU model simulations. 
TABLE 3. REI for near-surface temperature differences between the URB and NOU scenarios. Values $>1.025$ indicate the regional character of the effect; values equal to 1.0 show that there is no effect beyond urban land. Differences in the summer diurnal temperature range $\left(\mathrm{DTR}_{\mathrm{urb}-\mathrm{nou}}\right)$ and the maximum temperature $\left(\operatorname{Tmax}_{\mathrm{urb}-\mathrm{nou}}\right)$ show the strongest regional character (highlighted in boldface).

\begin{tabular}{ccc}
\hline \hline Variable & REI in Jan & REI in Jul \\
\hline Tmax $_{\text {urb }- \text { nou }}$ & 1.01 & $\mathbf{1 . 2 8}$ \\
Tmin $_{\text {urb }- \text { nou }}$ & 1.00 & 1.06 \\
DTR $_{\text {urb }- \text { nou }}$ & 1.01 & $\mathbf{1 . 3 7}$ \\
\hline
\end{tabular}

higher night sensible heat release (Figs. 3a,b) as they are included in UCM. The reduced evapotranspiration in combination with the additional anthropogenic heat flux leads to an increase of the near-surface temperature in urban areas; this effect is also known as urban heat island (Figs. 2c,d). In this study, the anthropogenic flux was prescribed constant throughout the day, so that it contributed continuously to the surface temperatures. However, the proportion of this contribution in relation to other heat fluxes of the surface energy balance varied in time. Shortwave radiation was governing the surface energy balance during the daylight hours, so that the contribution of the anthropogenic heat sources was smaller by an order of magnitude. During night hours, the contribution of the anthropogenic heat was greater and strongly influenced Tmin. This effect was also described in the work of Ichinose et al. (1999), who used time series of daily anthropogenic heat release of different sources in a modeling study of the urban climate in Tokyo, Japan. The authors found that the contribution of the anthropogenic heating is greater in winter than in summer because of the higher shortwave radiation in summer, which was dominant in the energy budget of the surface.

Differences in Tmax over urban areas indicated a reduction in Tmax in southern Europe by $-0.87^{\circ} \pm$ $0.39^{\circ} \mathrm{C}$ in summer and $-0.79^{\circ} \pm 0.18^{\circ} \mathrm{C}$ in winter (Figs. $2 \mathrm{e}, \mathrm{f})$. However, in regions with cooler climate, Tmax increased by $0.83^{\circ} \pm 0.21^{\circ} \mathrm{C}$ and $1.03^{\circ} \pm 0.35^{\circ} \mathrm{C}$ in summer and winter, respectively (Figs. 2e,f).

At high latitudes during wintertime, agricultural land or grassland may be covered by snow while buildings protrude above the snow cover and expose wall surfaces to the atmosphere. Walls of buildings are usually darker than snow, which provides a lower albedo of urban land. This leads to an absorption and accumulation of a larger amount of incoming solar radiation. Furthermore, buildings are heated to support the constant temperature inside $\left(20^{\circ} \mathrm{C}\right.$ in this study), which provides a temperature gradient between the inner building space and the colder outer atmosphere. This leads to a release of heat from buildings to the atmosphere by the diffusion of heat through the walls (as it is parameterized in the TEB component of the UCM scheme). These factors in combination with the drag force induced by buildings on the airflow (loss of momentum) resulted in an increase of near-surface temperature in wintertime simulations for cities at high latitudes.

In summertime, Tmax in urban areas was lower than in rural surroundings (Fig. 2f; urban areas of southern Europe). A similar result, the reduction of Tmax by $-0.02^{\circ} \pm 0.10^{\circ} \mathrm{C}$ annually over agricultural land in central California, was found by Christy and Norris (2006), who analyzed temperature time series recorded from 1910 to 2003. This effect was attributed to the massive growth in irrigated agriculture. However, for our study, the agricultural management was not changing throughout the simulations and the precipitation contribution to the soil moisture could not be significant in dry and hot summer conditions of southern Europe, where the largest Tmax reduction was found. The reduction of Tmax in urban areas can be explained by a combination of other factors. First, the inner building temperature is often lower than the temperature outside and there is a temperature gradient from the colder inner space of buildings to the warmer outer atmosphere. Second, the partial shading of street canyons (small sky view factor) leads to urban cooling; urban surfaces (roads, walls) that are not exposed to direct sunlight during the hottest daytime hours keep street canyons cooler than open rural areas. The situation when urban Tmax was lower than rural Tmax is illustrated by Fig. 4 for the Madrid urban area. In the morning hours, the rural temperature (over land with croplands) rises faster than the urban temperature because it is exposed to the sunlight at once, whereas urban surfaces remain largely shaded; at 0900 UTC the rural area is warmer by $2^{\circ} \mathrm{C}$ than the urban area, and at midday this temperature difference reaches up to $4^{\circ} \mathrm{C}$.

Figure 4 also shows an offset in phase between the urban and the rural diurnal temperature variations; the urban temperature reaches its highest value by $\sim 3 \mathrm{~h}$ later than the rural one. This can be explained by differences in the surface energy balance between the cropland and the city. The ground flux in the urban area is higher than in the rural area, which results from the lower urban albedo and lower canyon winds. The ground flux integrated over $24 \mathrm{~h}$ in the urban area is offset from the 0 level because of the additional sensible heat flux from anthropogenic sources (e.g., traffic, industry). As compared with the rural latent heat flux, the urban latent heat flux remains low because of the limited water availability for evaporation as a large 

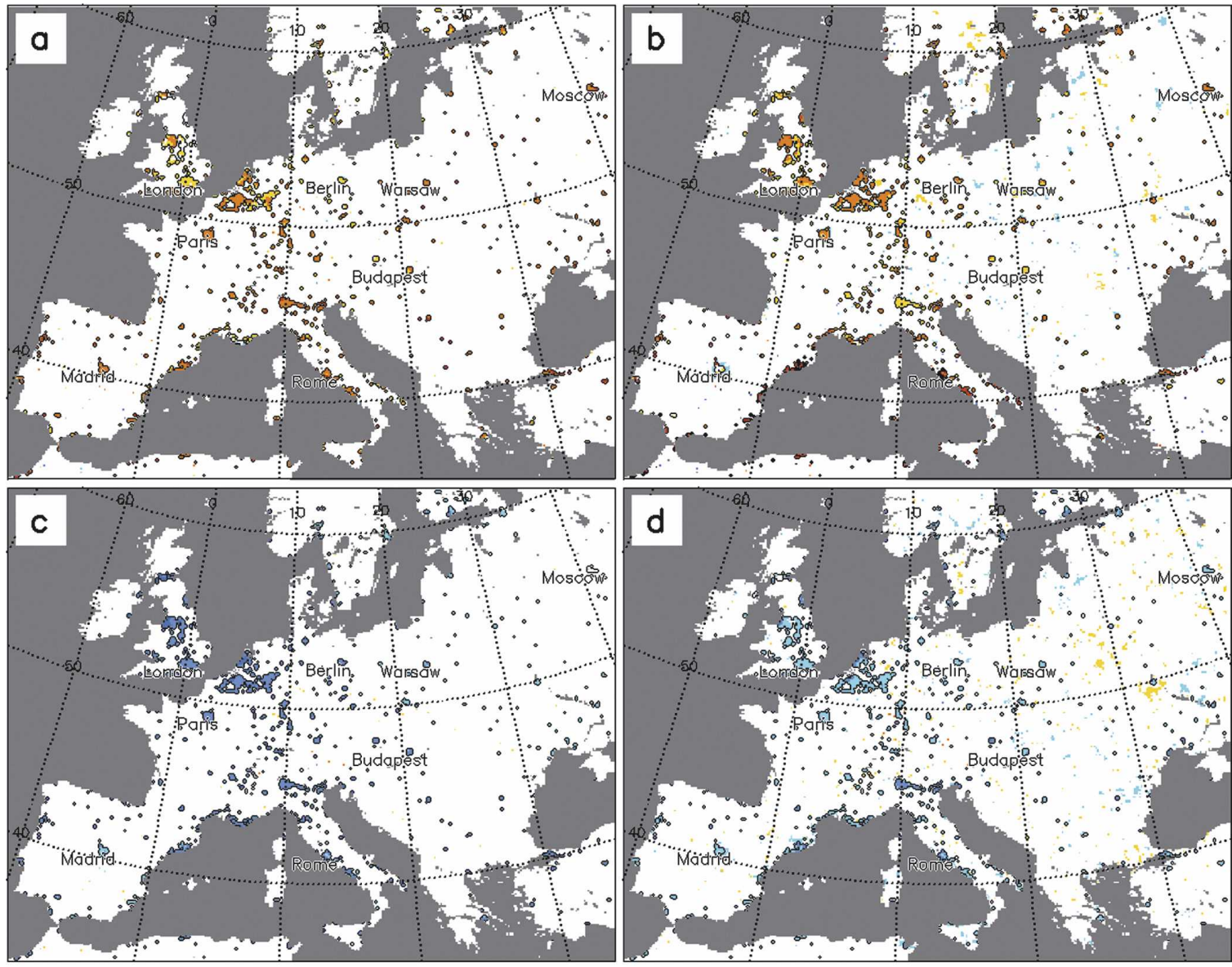

$-20$

$-15$

$-10$

$-5$

0

$+5+10+15$

$+20$

$[\mathrm{W} m-2]$

FIG. 3. Effects of urban land cover on surface energy fluxes $\left(\mathrm{W} \mathrm{m}^{-2}\right)$ at the night hour 0000 UTC for (left) January and (right) July. (a), (b) Difference in sensible heat flux $\left(\mathrm{SH}_{\mathrm{urb}-\text { nou }}\right)$ and (c), (d) difference in latent heat flux $\left(\mathrm{LH}_{\mathrm{urb}-\text { nou }}\right)$. Colored areas identify places of statistically significant differences between the URB and NOU model simulations.

amount of rainwater is lost to the drainage system as surface runoff. The combination of the large ground heat flux, higher heat capacity of urban surface materials, and partial shading of street canyons leads to a delay of the diurnal temperature peak in urban areas.

To find dependencies of the described effects on the climate conditions of the regions where the effects occur, the linear regression analysis was performed for the time series of $\mathrm{DTR}_{\mathrm{urb}-\mathrm{nou}}$, Tmax $\mathrm{mrr}_{\mathrm{urn}-\mathrm{nou}}$, and $\mathrm{Tmin}_{\text {urb-nou }}$ and the climate variables (mean monthly temperature and precipitation). The strongest correlation $(r>0.50)$ was found for $\operatorname{Tmax}_{\mathrm{urb}-\text { nou }}$ and the average daily temperature in January and July, and for Tmax $_{\mathrm{urb}-\text { nou }}$ and the average precipitation in July (Table 4). These correlations mean that a stronger increase of Tmax, induced by urban land cover, occurs in regions with lower mean temperatures and higher monthly precipitation, most likely in cool, temperate climates. There was no correlation found between Tmax $_{\mathrm{urb}-\mathrm{nou}}$ and the monthly precipitation in winter, because in this season rains are frequent across all of Europe.

\section{c. Effects of urban land cover on precipitation}

Our simulations showed that differences in daily precipitation between the NOU and URB scenarios were highly variable over the model domain (Fig. 5). Induced by the presence of urban land, significant differences in precipitation $\left(\mathrm{PR}_{\mathrm{urb}-\mathrm{nou}}\right)$ spread out far beyond urban areas and affected large rural surroundings. This was indicated by high values of REI: 6.4 in winter and 5.8 in summer.

Because of the large size of the model domain, which comprises areas with different climates and thus different monthly precipitation rates, we analyzed absolute $\left(\mathrm{PR}_{\mathrm{urb}-\mathrm{nou}}\right)$ and relative $\left(\Delta \mathrm{PR}_{\mathrm{urb}-\mathrm{nou}}\right)$ differences of 


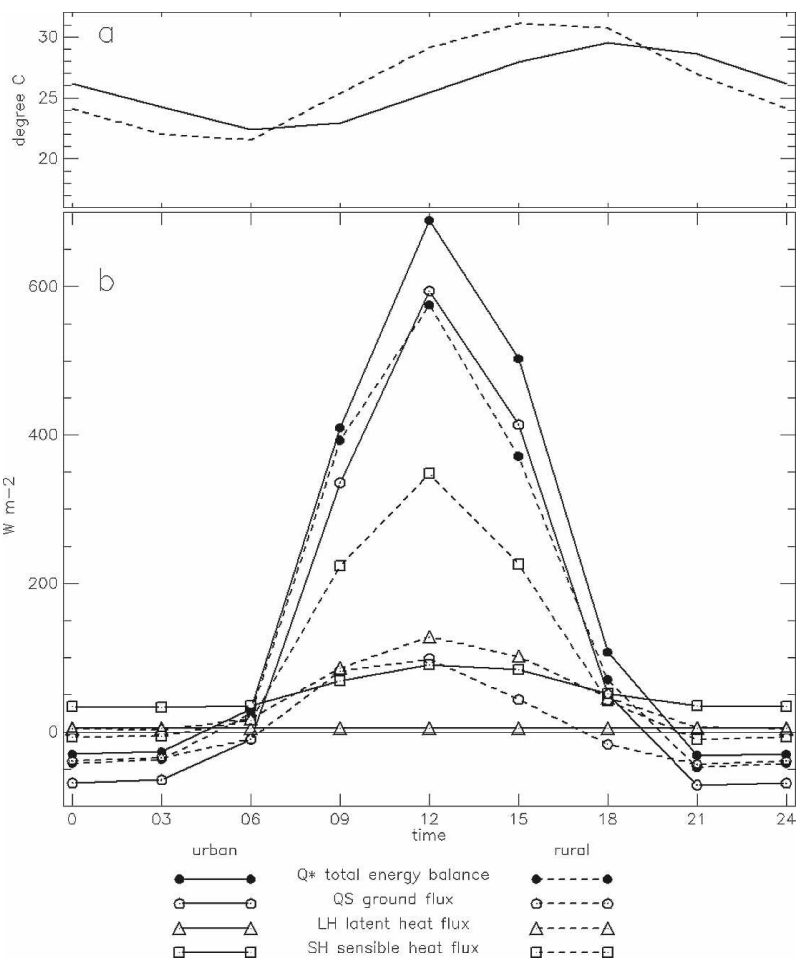

FIG. 4. (a) The near-surface temperature and (b) energy balance of urban and rural surfaces. Solid (dashed) lines represent urban (rural) areas. The data are 30-day averages of model simulations for Madrid in July 2005.

precipitation between the URB and NOU scenarios. The relative precipitation difference was calculated in the following way:

$$
\Delta \mathrm{PR}_{\mathrm{urb}-\mathrm{nou}}=100 \times \frac{\mathrm{PR}_{\mathrm{urb}-\mathrm{nou}}}{\mathrm{PR}_{\text {nou }}},
$$

where $\mathrm{PR}_{\text {nou }}$ is the absolute average monthly precipitation in the background simulation (no urban areas), $\mathrm{PR}_{\mathrm{urb}-\mathrm{nou}}$ is the absolute average difference of monthly precipitation between the URB and the background simulations, and $\Delta \mathrm{PR}_{\mathrm{urb}-\text { nou }}$ is relative to the background difference of monthly precipitation. In winter, the average $\mathrm{PR}_{\mathrm{urb}-\text { nou }}$ over land of the whole domain was as low as $-0.00 \pm 0.06 \mathrm{~mm} \mathrm{day}^{-1}(-0.07 \pm$ $\left.0.02 \mathrm{~mm} \mathrm{month}^{-1}\right)$. The precipitation differences were found mostly over urban areas and downwind from urban areas. The average $\mathrm{PR}_{\mathrm{urb}-\text { nou }}$ over urban land $\left(\mathrm{UPR}_{\mathrm{urb}-\mathrm{nou}}\right)$ and over rural land $\left(\mathrm{RPR}_{\mathrm{urb}-\text { nou }}\right)$ showed opposite trends accounting for $0.09 \pm 0.16 \mathrm{~mm}$ day $^{-1}$ and $-0.04 \pm 0.14 \mathrm{~mm} \mathrm{day}^{-1}$, respectively. The positive $\mathrm{UPR}_{\text {urb-nou }}$ was $0.21 \pm 0.14 \mathrm{~mm} \mathrm{day}^{-1}$, which makes for $\Delta \mathrm{UPR}_{\mathrm{urb}-\text { nou }}=8 \% \pm 4 \%$ of the background value calculated from the baseline scenario $\left(\mathrm{UPR}_{\mathrm{urb}}\right)$. As can be seen from Fig. 5a, the small cities tend to produce
TABLE 4. Correlation coefficients between the strength of urban effects on $\mathrm{Tmin}_{\mathrm{urb}-\mathrm{nou}}, \mathrm{Tmax}_{\mathrm{urb}-\mathrm{nou}}, \mathrm{DTR}_{\mathrm{urb}-\mathrm{nou}}$, and the climate variables: average temperature $\left(T_{\text {nou }}\right)$ and precipitation $\left(\mathrm{PR}_{\text {nou }}\right)$ of the background simulation. The three largest correlation coefficients are highlighted in boldface.

\begin{tabular}{lrr}
\hline \hline Correlated variables & Jan & \multicolumn{1}{c}{ Jul } \\
\hline$T_{\text {nou }}, \operatorname{Tmin}_{\text {urb-nou }}$ & 0.20 & -0.12 \\
PR $_{\text {nou }}, \mathrm{Tminx}_{\text {urb }- \text { nou }}$ & -0.06 & 0.14 \\
$T_{\text {nou }}, \operatorname{Tmax}_{\text {urb-nou }}$ & $-\mathbf{0 . 5 5}$ & $\mathbf{- 0 . 6 0}$ \\
PR $_{\text {nou }}, \mathrm{Tmax}_{\text {urb-nou }}$ & 0.00 & $\mathbf{0 . 6 0}$ \\
$T_{\text {nou }}, \mathrm{DTR}_{\text {urb-nou }}$ & -0.43 & -0.14 \\
PR $_{\text {nou }}, \mathrm{DTR}_{\text {urb-nou }}$ & 0.30 & 0.23 \\
\hline
\end{tabular}

increased rainfall downwind (the dominant winds were westerly), whereas large urban areas produced an increased rainfall over cities. This locality can be partly explained by the scheme for the cumulus parameterization used for model simulations. The precipitation increase over urban areas results from the enhanced convection forced by a UHI; higher surface temperatures provide an increase in the moist static energy of clouds and result in an increase of cloud water mixing ratio. When the saturation value is reached, the precipitation is initiated. The chosen cumulus parameterization includes no liquid cloud water and rainfall occurs as soon as the precipitation forms. After the rainfall over an urban area, the air mass becomes less saturated ("dry") and moves downwind. This urban intensified precipitation pattern resulted in reduced rural precipitation $\left(\mathrm{RPR}_{\mathrm{urb}-\mathrm{nou}}\right)$ by $-0.12 \pm 0.11 \mathrm{~mm} \mathrm{day}^{-1}$, which is $-4 \% \pm 3 \%$ of the background value $\mathrm{RPR}_{\text {nou }}$. Possible mislocation of simulated precipitation patterns due to the model setup were considered of minor importance for the performed analysis, because in this study we do not look for the exact location of precipitation anomalies but rather give a quantitative estimation of urbanization-induced precipitation changes over a long period of time.

In summer, the average $\mathrm{PR}_{\text {urb-nou }}$ over land of the whole domain was $-0.03 \pm 0.25 \mathrm{~mm} \mathrm{day}^{-1}(-1.05 \pm$ $\left.1.31 \mathrm{~mm} \mathrm{month}^{-1}\right)$. The precipitation differences were highly variable over the domain and they could be classified in three groups by geographical location. Multiple urban areas situated in coastal regions and inland between $15^{\circ}$ and $30^{\circ} \mathrm{E}$ (EAST_EU) exhibited enhanced rainfall (Fig. 5b) $\left(\mathrm{UPR}_{\text {urb }- \text { nou }}=0.18 \pm 0.19 \mathrm{~mm} \mathrm{day}^{-1}\right)$. Urban areas between $10^{\circ} \mathrm{W}$ and $15^{\circ} \mathrm{E}$ and $45^{\circ}$ and $55^{\circ} \mathrm{N}$ (CENTRE_EU) as well as urban areas between $10^{\circ} \mathrm{W}$ and $15^{\circ} \mathrm{E}$ and $35^{\circ}$ and $45^{\circ} \mathrm{N}$ (SOUTH_EU) mainly had reduced rainfall over cities by $\mathrm{UPR}_{\text {urb-nou }}=-0.41 \pm$ $0.35 \mathrm{~mm} \mathrm{day}{ }^{-1}$, which was lower than $\mathrm{UPR}_{\text {nou }}$ by $-19 \% \pm 15 \%$. The similar effect on the water balance was found by Lamptey et al. (2005) with de- 


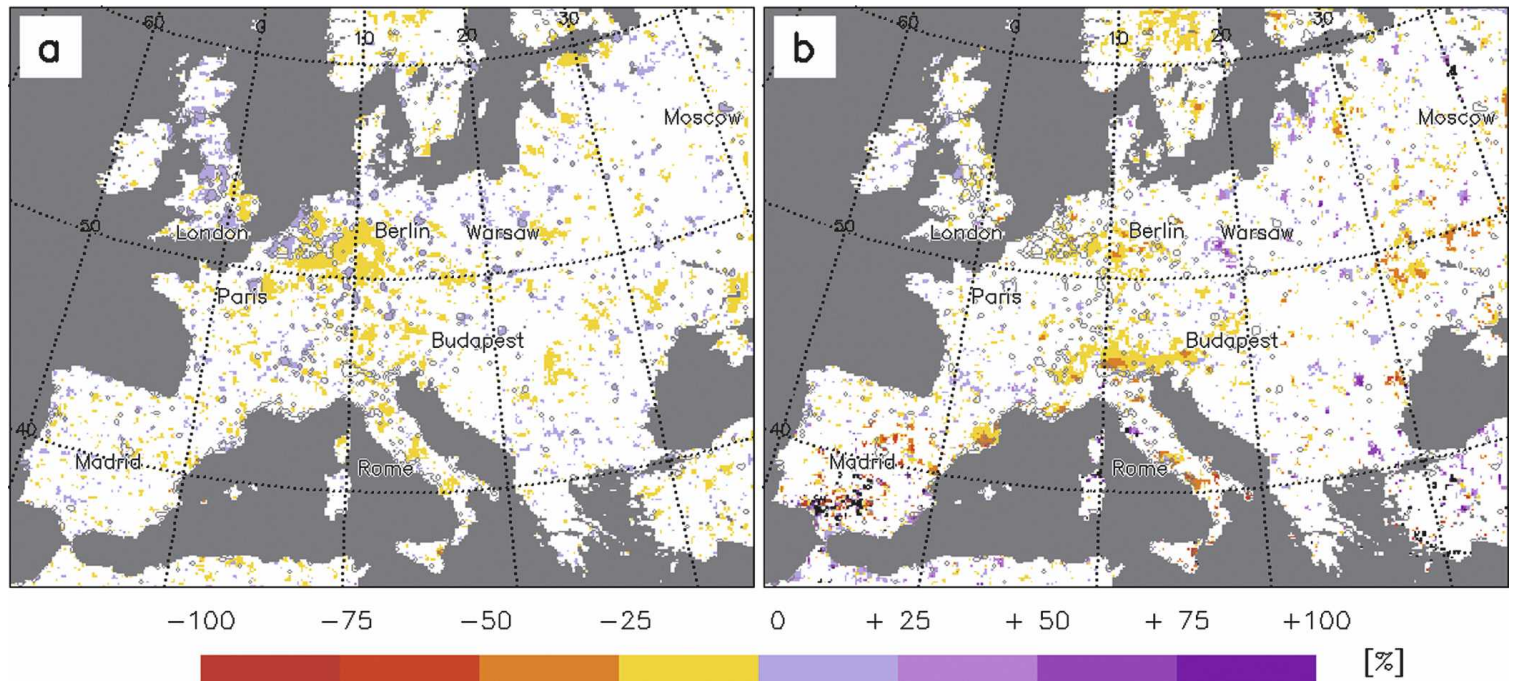

FIG. 5. Effects of urban land cover on daily precipitation (\%) are shown relative to the baseline daily precipitation differences $\Delta \mathrm{PR}_{\mathrm{urb}-\mathrm{nou}}(\%)$ for (a) January and (b) July simulations.

creased convective rainfall in summer. In rural areas in CENTRE_EU and SOUTH_EU regions, significant values of $R_{P R} R_{u r b-n o u}$ were found mainly downwind (southeast) of urban areas and accounted for $-0.55 \pm$ $0.52 \mathrm{~mm} \mathrm{day}^{-1}\left(\Delta \mathrm{RPR}_{\mathrm{urb}-\mathrm{nou}}=-18 \pm 15 \%\right)$.

The differences in effects on precipitation among EAST_EU, CENTRE_EU, and SOUTH_EU regions can be explained by differences in the climate of these regions. The region of SOUTH_EU has a Mediterranean climate with dry and hot summers $(\mathrm{Cfb}$, here and below the climate class according to Köppen's climate classification), whereas CENTRE_EU has maritime west coast climates (Csa, Csb) and EAST_EU is largely influenced by a humid continental climate (Dfb). In SOUTH_EU, the air humidity during dry, hot (clearsky conditions) summers is low in urban areas, and additionally, the removal of water into the surface runoff cuts off the contribution from the surface evaporation to the precipitation formation. The values of the relative precipitation change $\Delta \mathrm{PR}_{\mathrm{urb}-\text { nou }}$ in SOUTH_EU reached up to a $30 \%$ reduction because the background value $\mathrm{PR}_{\text {nou }}$ was rather small. In EAST_EU, summers are humid and urban heating forces the convection and precipitation formation (similar to the situation described above for the winter simulations). In the CENTER_EU region, summers are generally mild and precipitation is frequent; thus the reduction of precipitation can be explained by the reduced surface water availability in the extensive urban areas of this region.

Various measurement studies reported an increase of precipitation in urban areas and downwind of urban areas (Shepherd et al. 2002; Changnon et al. 1991; Jauregui 1991; Huff and Changnon 1973). However, it is difficult to compare the results of our study with the observations for two reasons: 1) most reported observations of precipitation were done within the tropical region between $32^{\circ} \mathrm{N}$ and $32^{\circ} \mathrm{S}$ (Shepherd et al. 2002; Rosenfeld 2000; Changnon et al. 1991), which does not include Europe, and 2) these studies compared the rainfall downwind of the city with the rainfall upwind of the city, but in our study we compared the rainfall simulated with and without urban areas. The latter argument is important for the correct interpretation of the results: we estimated the contribution of urban land to precipitation, but we did not quantify modifications of precipitation patterns by existing urban areas; we compared two simulated states of atmospheric circulation, while the observational studies analyzed only one that is influenced by urban surfaces.

The analysis of the dependence between $\mathrm{PR}_{\mathrm{urb}-\mathrm{nou}}$ and climate variables did not show any significant correlation (correlation coefficients were always $<0.02$ ) for either region.

\section{Conclusions}

This study suggested that urban land cover makes a significant contribution to changes of near-surface temperatures and precipitation on local and regional scales. It was found that locally urban land use induces a significant reduction of the diurnal temperature range by more than $-1.2^{\circ} \mathrm{C}$ in summertime and by more than $-0.7^{\circ} \mathrm{C}$ in wintertime. Changes in atmospheric circulation due to urban land resulted in an increase of winter precipitation by $\sim 8 \%$ and in a reduction of summer precipitation by $\sim 19 \%$ in European cities. It was shown 
that urban land use strongly affects not only the local climate in cities but the climate of urban surroundings as well. This result is especially important for predicting impacts of urban growth on local and regional climates.

However, two additional factors were not included in this study: 1) the effects of urban pollution on precipitation formation (Rosenfeld 2000) and on the surface radiation budget (Stanhill and Kalma 1995) and 2) the differential representation of morphology and anthropogenic heat sources for each individual city. The latter issue shows a necessity for developing a new database that will contain a standardized information structure and functionality of multiple individual cities.

Acknowledgments. We thank the Max-PlanckGesellschaft for providing the scholarship to Kristina Trusilova, DKRZ (Deutsches Klimarechenzentrum $\mathrm{GmbH}$ ) for providing computer facilities, the MM5 developing team at NCAR for the model support, and the Analysis, Integration and Modeling of the Earth System (AIMES) for the financial support for presenting results of this work at the First International Conference on Carbon Management at Urban and Regional Levels (Mexico City, Mexico, 9-10 September 2006).

We especially thank Dr. J. Schumacher for consulting with the statistics and Prof. S. Grimmond for fruitful discussions and useful suggestions on the modeling work.

\section{REFERENCES}

Alonso, M. S., J. L. Labajo, and M. R. Fidalgo, 2003: Characteristics of the urban heat island in the city of Salamanca, Spain. Atmósfera, 16, 137-148.

Atkinson, B. W., 2002: Numerical modelling of urban heat-island intensity. Bound.-Layer Meteor., 109, 285-310.

Bernatzky, A., 1982: The contribution of trees and green spaces to a town climate. Energ. Build., 5, 1-10.

Borghi, S., G. Corbetta, and L. De Biase, 2000: A heat island model for large urban areas and its application to Milan. Nuovo Cimento, 23C, 547-566.

Bottyan, Z., A. Kircsi, S. Szegedi, and J. Unger, 2005: The relationship between built-up areas and the spatial development of the mean maximum urban heat island in Debrecen, Hungary. Int. J. Climatol., 25, 405-418.

Brunetti, M., F. Mangianti, M. Maugeri, and T. Nanni, 2000: Urban heat island bias in Italian air temperature series. Nuovo Cimento, 23C, 423-431.

Ca, V. T., T. Asaeda, and E. M. Abu, 1998: Reductions in air conditioning energy caused by a nearby park. Energ. Build., 29, 83-92.

Changnon, S. A., R. T. Shealy, and R. W. Scott, 1991: Precipitation changes in fall, winter, and spring caused by St. Louis. $J$. Appl. Meteor., 30, 126-134.

Chen, F., and J. Dudhia, 2001a: Coupling an advanced land surface-hydrology model with the Penn State-NCAR MM5 modeling system. Part I: Model implementation and sensitivity. Mon. Wea. Rev., 129, 569-586.
_ , and — 2001b: Coupling an advanced land surfacehydrology model with the Penn State-NCAR MM5 modeling system. Part II: Preliminary model validation. Mon. Wea. Rev., 129, 587-604.

Christy, J. R., W. B. Norris, K. Redmond, and K. P. Gallo, 2006: Methodology and results of calculating central California surface temperature trends: Evidence of human-induced climate change? J. Climate, 19, 548-563.

Dixon, P. G., and T. L. Mote, 2003: Patterns and causes of Atlanta's urban heat island-initiated precipitation. J. Appl. Meteor., 42, 1273-1284.

Dudhia, J., 1989: Numerical study of convection observed during the Winter Monsoon Experiment using a mesoscale twodimensional model. J. Atmos. Sci., 46, 3077-3107.

Ek, M. B., K. E. Mitchell, Y. Lin, E. Rogers, P. Grunmann, V. Koren, G. Gayno, and J. D. Tarpley, 2003: Implementation of Noah land surface model advances in the National Centers for Environmental Prediction operational mesoscale Eta model. J. Geophys. Res., 108D, 8851, doi:10.1029/ 2002JD003296.

Elvidge, C. D., K. E. Baugh, V. R. Hobson, E. A. Kihn, H. W. Kroehl, E. R. Davis, and D. Cocero, 1997: Satellite inventory of human settlements using nocturnal radiation emissions: A contribution for the global toolchest. Global Change Biol., 3, 387-395.

,-- J. B. Dietz, T. Bland, P. C. Sutton, and H. W. Kroehl, 1999: Radiance calibration of DMSP-OLS low-light imaging data of human settlements: A new device for portraying the Earth's surface entire. Remote Sens. Environ., 68, 77-88.

González, J. E., and Coauthors, 2005: Urban heat islands developing in coastal tropical cities. Eos, Trans. Amer. Geophys. Union, 86, 397-403.

Grell, G. A., J. Dudhia, and D. R. Stauffer, 1995: A description of the fifth-generation Penn State/NCAR Mesoscale Model (MM5). NCAR Tech. Note NCAR/TN-398+STR, 122 pp.

Grimmond, C. S. B., and T. R. Oke, 1999: Evapotranspiration rates in urban areas. Impacts of Urban Growth on Surface Water and Groundwater Quality, B. Ellis, Ed., IAHS Publication 259, 235-244.

Hong, S.-Y., and H.-L. Pan, 1996: Nonlocal boundary layer vertical diffusion in a medium-range forecast model. Mon. Wea. Rev., 124, 2322-2339.

Huang, Y. J., H. Akbari, H. Taha, and A. H. Rosenfeld, 1987: The potential of vegetation in reducing summer cooling loads in residential buildings. J. Climate Appl. Meteor., 26, 1103-1116.

Huff, F. A., and S. A. Changnon Jr., 1973: Precipitation modification by major urban areas. Bull. Amer. Meteor. Soc., 54, $1220-1232$.

Hupfer, P., and F. M. Chmielewski, 1990: Das Klima von Berlin. Akademie-Verlag, 288 pp.

Ichinose, T., K. Shimodozono, and K. Hanaki, 1999: Impact of anthropogenic heat on urban climate in Tokyo. Atmos. Environ., 33, 3897-3909.

Idso, C. D., S. B. Idso, and R. C. Balling Jr., 2001: An intensive two-week study of an urban $\mathrm{CO}_{2}$ dome in Phoenix, Arizona, USA. Atmos. Environ., 35, 995-1000.

Imhoff, M. L., W. T. Lawrence, D. C. Stutzer, and C. D. Elvidge, 1997: A technique for using composite DMSP/OLS "city lights" satellite data to map urban area. Remote Sens. Environ., 61, 361-370.

Jauregui, E., 1991: Influence of a large urban park on temperature and convective precipitation in a tropical city. Energ. Build., 15, 457-463. 
Jin, M., R. E. Dickinson, and D. Zhang, 2005: The footprint of urban areas on global climate as characterized by MODIS. $J$. Climate, 18, 1551-1565.

Jones, P. D., P. Ya. Groisman, M. Coughlan, N. Plummer, W.-C. Wang, and T. R. Karl, 1990: Assessment of urbanization effects in time series of surface air temperature over land. $\mathrm{Na}$ ture, 347, 169-172.

Kalnay, E., and M. Cai, 2003: Impact of urbanization and land-use change on climate. Nature, 423, 528-531.

Klysik, K., and K. Fortuniak, 1999: Temporal and spatial characteristics of the urban heat island of Lodz, Poland. Atmos. Environ., 33, 3885-3895.

Koerner, B., and J. Klopatek, 2002: Anthropogenic and natural $\mathrm{CO}_{2}$ emission sources in an arid urban environment. Environ. Pollut., 116, S45-S51.

Kukla, G., J. Gavin, and T. R. Karl, 1986: Urban warming. J. Climate Appl. Meteor., 25, 1265-1270.

Kusaka, H., H. Kondo, Y. Kikegawa, and F. Kimura, 2001: A simple single-layer urban canopy model for atmospheric models: Comparison with multi-layer and slab models. Bound.-Layer Meteor., 101, 329-358.

Lamptey, B. L., E. J. Barron, and D. Pollard, 2005: Impacts of agriculture and urbanization on the climate of the northeastern United States. Global Planet. Change, 49, 203-221.

Lavalle, C., and Coauthors, 2002: Towards an urban atlas: Assessment of spatial data on 25 European cities and urban areas. Environmental Issue Rep. 30, European Environment Agency, 131 pp. [Available online at http://reports.eea. europa.eu/environmental_issue_report_2002_30/en.]

Loveland, T. R., B. C. Reed, J. F. Brown, D. O. Ohlen, Z. Zhu, L. Yang, and J. W. Merchant, 2000: Development of a global land cover characteristics database and IGBP DISCover from 1 km AVHRR data. Int. J. Remote Sens., 21, 1303-1330.
Martilli, A., A. Clappier, and M. W. Rotach, 2002: An urban surface exchange parameterisation for mesoscale models. Bound.-Layer Meteor., 104, 261-304.

Masson, V., 2000: A physically-based scheme for the urban energy budget in atmospheric models. Bound.-Layer Meteor., 94, 357-397.

Mayer, H., A. Matzarakis, and M. G. Iziomon, 2003: Spatiotemporal variability of moisture conditions within the urban canopy layer. Theor. Appl. Climatol., 76, 165-179.

Montávez, J. P., A. Rodríguez, and J. I. Jiménez, 2000: A study of the urban heat island of Granada. Int. J. Climatol., 20, 899911.

Müller, M., 1996: Handbuch ausgewählter Klimastationen der Erde. University of Trier Press, 33-132.

Parker, D. E., 2004: Climate: Large-scale warming is not urban. Nature, 432, 290.

Rosenfeld, D., 2000: Suppression of rain and snow by urban and industrial air pollution. Science, 287, 1793-1796.

Shepherd, J. M., and M. Jin, 2004: Linkages between the built urban environment and Earth's climate system. Eos, Trans. Amer. Geophys. Union, 85, 227-228.

- H. Pierce, and A. J. Negri, 2002: Rainfall modification by major urban areas: Observations from spaceborne rain radar on the TRMM satellite. J. Appl. Meteor., 41, 689-701.

Stanhill, G., and J. D. Kalma, 1995: Solar dimming and urban heating at Hong Kong. Int. J. Climatol., 15, 933-941.

Unger, J., Z. Sümeghy, and J. Zoboki, 2001: Temperature crosssection features in an urban area. Atmos. Res., 58, 117-127.

Wood, F. B., 1988: Comment: On the need for validation of the Jones et al. temperature trends with respect to urban warming. Climatic Change, 12, 297-312. 